\title{
Desempenho de bezerros alimentados usando de sucedâneo até 56 dias de idade ${ }^{1}$
}

\author{
Silvia Resende de Albuquerque França2, Sandra Gesteira Coelho ${ }^{3}$, Antônio Ultimo de Carvalho ${ }^{3}$, \\ Renè Galvão Rezende Martins ${ }^{4}$, Sergio Luiz Moreira Ribeiro ${ }^{5}$
}

\section{RESUMO}

Trinta bezerros machos da raça Holandesa foram alojados em piquetes a partir do quinto dia de vida, distribuídos em dois grupos. Todos os animais foram alimentados com concentrado comercial peletizado, tendo o primeiro grupo recebido leite integral (grupo-controle) e o outro, sucedâneo formulado com proteínas de soja, de soro de leite e de leite desnatado em pó (grupo tratamento), num único horário de fornecimento, até 56 dias de vida. Os animais tinham acesso ad libitum à água e ao sal mineral. Suas medidas de peso vivo e altura de ísquio foram tomadas semanalmente. $\mathrm{O}$ desenvolvimento em estatura não diferiu entre os tratamentos, e o ganho em peso foi inferior para os animais alimentados com sucedâneo. O menor ganho em peso foi influenciado pelo menor consumo de concentrado e de matéria seca da dieta.

Palavras-chave: Bezerros, sucedâneos, sistemas de aleitamento.

\begin{abstract}
\section{Performance of calves fed milk replacer until 56 days of age}

Thirty male Holstein calves were designed to two groups, kept in pasture since they were five days, and they were fed with commercial pelleted starter concentrate, and whole milk (control group) or milk replacer made with soy protein, wheat milk and whey (treatment group), in one hour a day, until 56 days. The calves had access ad libitum to water and mineral salt. Everyone was weighted weekly, and measured. The stature development didn't differ between treatments, but the weight gains were minor for the calves fed with milk replacer, what reflected on their body scores. The body weight gain was affected by the consume of concentrate, and by the dry matter of the liquid diet, because of the decantation of this product occurred during the supply.
\end{abstract}

Key words: Calves, substitutes, feeding systems.

\footnotetext{
Recebido para publicação em 05/03/2009 e aprovado em 03/11/2011

${ }^{1}$ Projeto desenvolvido em parceria com Agroceres

${ }^{2}$ Médica Veterinária, Doutora. Secretaria de Estado de Saúde de Minas Gerais, Gerência Regional de Saúde de Sete Lagoas, Rua Fernando Lanza, 70, Centro, 35700-545, Sete Lagoas, Minas Gerais, Brasil. silviaraf@yahoo.com.br

${ }^{3}$ Médicos Veterinários, Doutores. Universidade Federal de Minas Gerais, Escola de Veterinária, Av. Antônio Carlos 6627, Caixa Postal 567, campus Pampulha da UFMG, 30123970. Belo Horizonte, Minas Gerais, Brasil. sandra@vet.ufmg.br, ultimo@vet.ufmg.br

${ }^{4}$ Médico Veterinário, Doutor. Tortuga Companhia Zootécnica Agrária. Rua Lindolfo de Azevedo, 1122, Jardim América, 30421-382. Belo Horizonte/MG renegalvao@ yahoo.com

${ }^{5}$ Médico Veterinário, Mestre. Valor Representações Ltda, Rua Sete de Setembro, 2156, Centro, 35595-000, Luz, Minas Gerais, Brasil.Sergio@valoragropecuaria.com.br
} 


\section{INTRODUÇÃO}

O desempenho de bezerros pode ser afetado por alguns fatores, como nutricional, sanitários e genéticos. Os ganhos em peso sofrem variação conforme a idade, sendo normalmente inferiores antes da desmama (Quigley III $e t$ al., 1991). Algumas patologias podem interferir no desenvolvimento de bezerros (Virtala et al., 1996), havendo estreita relação entre o desenvolvimento fisiológico do trato digestivo e o peso à desmama (Plaza \& Fernandez, 1999). Entretanto, a nutrição é a principal responsável pelo desempenho animal. Os sucedâneos vêm sendo amplamente utilizados na nutrição dessa categoria animal, visando à redução dos custos de criação nessa fase e ao maior aproveitamento do leite obtido no sistema para a comercialização. No entanto, são encontrados diversos tipos de sucedâneos formulados com alimentos variados, proporcionando diferentes desempenhos. Dentre os componentes do sucedâneo, a fonte proteica é considerada a maior influenciadora nas respostas animais. Dawson et al. (1988) observaram que bezerros recebendo sucedâneo composto por proteína de soja processada por diferentes métodos obtinham ganhos em peso inferiores aos do grupo leite durante as seis primeiras semanas de vida, havendo diferenças de desempenho em razão dos diferentes tipos de processamento ao longo do experimento. Neste trabalho objetivou-se avaliar o desenvolvimento animal proporcionado pelo consumo de sucedâneo comercial, contendo proteína de origem vegetal processada por micronização, em comparação ao consumo de leite integral por bezerros machos da raça Holandesa até os 90 dias de idade.

\section{MATERIAL E MÉTODOS}

O experimento foi conduzido na Escola de Veterinária da UFMG. Foram utilizados 30 bezerros machos da raça Holandesa; no primeiro dia de vida todos receberam colostro fornecido em duas vezes, e durante os quatro dias subsequentes, dois litros de leite integral pela manhã e dois à tarde. A partir do quinto dia, eles foram designados a um dos dois grupos experimentais, tendo um recebido leite e o outro sucedâneo formulado com proteínas de soja micronizada de soro de leite e de leite desnatado em pó, em um único horário de fornecimento até a desmama, aos 56 dias de idade. Todos receberam ainda concentrado inicial peletizado e sal mineral ad libitum (Tabelas 1 e 2).

Os alimentos fornecidos, bem como suas sobras, foram analisados bioquimicamente, conforme AOAC (1980). Semanalmente todos os animais eram pesados antes do fornecimento do leite ou sucedâneo e da troca do concentrado nos cochos, em balança "açores", com capacidade de $2.000 \mathrm{~kg}$, precisão de $100 \mathrm{~g}$, e tinham suas alturas de ísquio mensuradas com o uso de uma trena com nível, adaptada a uma régua de madeira que servia para nivelar o ponto de tomada da medida. Essas medidas foram feitas dentro da própria balança, a fim de padronizar o piso e evitar falhas por desnivelamento. Nessa ocasião era feita a avaliação de escore corporal pontuando os animais de 1 a 5. Os bezerros continuaram com as mesmas avaliações da desmama até os 90 dias de idade. Nesse período, permaneceram com acesso livre ao concentrado comercial, ao sal mineral e à água. Os dados de desempenho foram agrupados em três períodos, a cada 30 dias, para promover melhor avaliação dos resultados. Os valores obtidos foram analisados utilizando-se o procedimento General Linear Model (GLM) da versão 6.12 do programa SAS (1997), para ajustar um modelo linear que incluiu os efeitos fixos da média geral e de tratamentos mais o efeito aleatório do erro experimental. Para testar as diferenças entre as médias, foi empregado o teste estatístico de Student Newman Keus (SNK), a 5\% de probabilidade.

\section{RESULTADOS E DISCUSSÃO}

Conforme apresentado na Tabela 3, os pesos médios dos bezerros até 14 dias de idade não diferiram entre os dois grupos, que estavam em fase de adaptação, além de

Tabela 1. Teores médios de matéria seca (MS), proteína bruta (PB), fibra em detergente neutro (FDN), fibra em detergente ácido (FDA), nutrientes digestíveis totais (NDT), fibra bruta (FB), cálcio $(\mathrm{Ca})$, fósforo $(\mathrm{P})$ e extrato etéreo $(\mathrm{EE})$ dos sólidos do leite, do concentrado e do sucedâneo, expressos em porcentagem da matéria seca

\begin{tabular}{lccc}
\hline & Sólidos do leite & Sucedâneo & Concentrado \\
\hline MS & 100 & 93,46 & 89,91 \\
PB & 25,6 & 23,48 & 20,98 \\
FDN & & & 27,56 \\
FDA & & & 11,15 \\
NDT & & & 85,83 \\
FB & & & 6,26 \\
Minerais & 5,6 & 8,62 & 7,23 \\
Ca & 0,95 & 1,16 & 1,22 \\
P & 0,76 & 0,78 & 0,77 \\
EE & 29,6 & 20,76 & 5,31 \\
\hline
\end{tabular}

Tabela 2. Níveis de garantia dos elementos ativos do mineral por $\mathrm{kg}$ do produto

\begin{tabular}{lc}
\hline Nutriente & $\mathbf{g} / \mathbf{k g}$ \\
\hline Cálcio (máx.) & $120 \mathrm{~g}$ \\
Fósforo (min.) & $87 \mathrm{~g}$ \\
Flúor (máx.) & $0,87 \mathrm{~g}$ \\
Cobre & $1.500 \mathrm{mg}$ \\
Zinco & $3.600 \mathrm{mg}$ \\
Manganês & $1.300 \mathrm{mg}$ \\
Ferro & $1.800 \mathrm{mg}$ \\
Cobalto & $200 \mathrm{mg}$ \\
Selênio & $12 \mathrm{mg}$ \\
NaCl & qsp $1.000 \mathrm{~g}$ \\
\hline
\end{tabular}

Rev. Ceres, Viçosa, v. 58, n.6, p. 790-793, nov/dez, 2011 
Tabela 3. Peso $(\mathrm{kg})$ e altura de ísquio $(\mathrm{cm})$ de bezerros Holandeses alimentados com leite ou com sucedâneo do nascimento aos 90 dias de idade

\begin{tabular}{|c|c|c|c|c|}
\hline \multirow[t]{2}{*}{ Idade (dias) } & \multicolumn{2}{|c|}{ Kg } & \multicolumn{2}{|c|}{ cm } \\
\hline & Leite & Sucedâneo & Leite & Sucedâneo \\
\hline Inicial & $38,6^{\mathrm{a}}$ & $38,31^{a}$ & - & - \\
\hline 7 & $41,4^{\mathrm{a}}$ & $41,4^{\mathrm{a}}$ & $75,40^{a}$ & $76,50^{\mathrm{a}}$ \\
\hline 14 & $40,6^{a}$ & $39,8^{a}$ & 76,79 & - \\
\hline 21 & $43,4^{\mathrm{a}}$ & $38,4^{\mathrm{b}}$ & $78,90^{\mathrm{a}}$ & $77,60^{\mathrm{a}}$ \\
\hline 28 & $47,0^{\mathrm{a}}$ & $39,0^{\mathrm{b}}$ & $79,89^{a}$ & $77,92^{a}$ \\
\hline 35 & $49,0^{\mathrm{a}}$ & $43,2^{\mathrm{a}}$ & $80,96^{\mathrm{a}}$ & $79,29^{a}$ \\
\hline 42 & $54,1^{a}$ & $43,6^{\mathrm{a}}$ & $82,72^{a}$ & $80,05^{\mathrm{a}}$ \\
\hline 49 & $63,4^{a}$ & $53,3^{\mathrm{b}}$ & $85,34^{a}$ & 81,24 b \\
\hline 56 & $70,7^{\mathrm{a}}$ & $57,3^{\mathrm{b}}$ & $88,17^{\text {a }}$ & $82,06^{\mathrm{b}}$ \\
\hline 63 & $77,3^{a}$ & $65,2^{a}$ & $89,92^{\mathrm{a}}$ & $88,33^{\mathrm{a}}$ \\
\hline 70 & $84,2^{\text {a }}$ & $71,2^{a}$ & $91,30^{\mathrm{a}}$ & $88,75^{\text {a }}$ \\
\hline 77 & $94,4^{\text {a }}$ & $77,2^{\text {a }}$ & $92,00^{\mathrm{a}}$ & $90,10^{\mathrm{a}}$ \\
\hline 90 & $110,4^{\mathrm{a}}$ & $86,76^{\mathrm{b}}$ & $93,37^{\text {a }}$ & $90,96^{\mathrm{a}}$ \\
\hline
\end{tabular}

Letras diferentes na linha indicam diferenças entre tratamentos. Teste SNK; $p<0,05$.

que os ganhos em peso normalmente são modestos até a segunda semana.

A Tabela 3 apresenta o peso e a altura de ísquio dos animais a cada sete dias, alimentados com leite ou com sucedâneo nas diferentes idades avaliadas.

Os bezerros do grupo sucedâneo apresentaram ganho em peso de $48 \mathrm{~kg}$ em média até os 90 dias, considerados proporcionalmente elevados quando comparados aos obtidos por Seegraber \& Morril (1982) fornecendo apenas dieta líquida aos animais. Lalles et al. (1995) observaram ganhos semelhantes para bezerro, comparando proteínas láctea e de soja, sendo esses superiores aos obtidos no presente trabalho, provavelmente devido à desmama mais tardia. A menor concentração de enzimas proteolíticas no trato gastrointestinal de bezerros e a menor capacidade das enzimas digestivas dos bezerros de hidrolisar proteínas não lácteas têm sido citadas como possível explicação para a menor digestibilidade observada em bezerros alimentados com sucedâneo, contendo fontes proteicas não lácteas (Silva et al, 1986). A altura dos bezerros não foi afetada pelas dietas avaliadas, exceto as idades de 49 e 56 dias. Lammers et al. (1998) obtiveram ganhos semelhantes para bezerros alimentados com sucedâneos à base de proteínas lácteas até 42 dias de vida, quando eles tinham acesso ao concentrado ad libitum, mas inferiores quando apenas era fornecida a dieta líquida. As ocorrências sanitárias que foram registradas durante o experimento não interferem na estatura dos animais, de acordo com achados de Virtala et al. (1996).

Pela Tabela 4 pode-se observar que os ganhos em peso dos bezerros alimentados com sucedâneo foram inferiores aos do grupo-controle, exceto para o primeiro período, quando ocorreram alguns casos de diarreia nos bezerros alimentados com leite afetando os desempenhos individuais, conforme previamente demonstrado por Virtala et al. (1996), proporcionando elevado coeficiente de variação para essa característica.

No segundo período, os ganhos foram inferiores para os bezerros que recebiam sucedâneo (Tabela 4), o qual apresentou sedimentação durante o fornecimento, de modo que tornava baixo o consumo de matéria seca pelos animais, levando-os a um déficit nutricional, já que o consumo de concentrados nessa fase era semelhante para os dois grupos. No terceiro período, após a desmama, o consumo de concentrados foi superior para os animais que haviam sido alimentados com leite, correspondendo também ao maior ganho em peso por esses bezerros nessa fase. Os animais que desmamaram mais pesados permaneceram mais pesados ao final do experimento, de acordo com o descrito por Plaza \& Fernadez (1999). Houve ganho crescente para ambos os grupos com o aumento da idade. Os ganhos até a desmama (56 dias) foram inferiores para os animais que receberam sucedâneo, tendo os pesos não apresentado diferenças nas três semanas subsequentes, demonstrando ganho compensatório pelos animais.

Tabela 4. Ganho em peso médio diário, em kg, de bezerros machos da raça Holandesa, alimentados com leite ou sucedâneo por períodos ( $1=1$ a 30 dias, $2=31$ a 60 dias e $3=61$ a 90 dias $)$

\begin{tabular}{lcc}
\hline Período & Leite & Sucedâneo \\
\hline 1 & $0.37 \mathrm{a}$ & $0.28 \mathrm{a}$ \\
2 & $1.46 \mathrm{a}$ & $0.94 \mathrm{~b}$ \\
3 & $2.03 \mathrm{a}$ & $1.33 \mathrm{~b}$ \\
\hline
\end{tabular}

Letras diferentes na mesma linha indicam diferenças entre tratamentos. Teste SNK; p < 0,05; CV (período 1) $=97,56 ; \mathrm{CV}$ $($ período 2$)=31,91 ;$ e $\mathrm{CV}($ período 3$)=22,31$. 


\section{CONCLUSÕES}

Os menores ganhos em peso ocorridos para o grupo sucedâneo mostram menor utilização da proteína da soja frente à do leite. Os eventos digestivos, bem como a apresentação do próprio sucedâneo, parecem ter sido responsáveis por esses resultados, além do menor consumo de concentrados desencadeado pela dieta.

\section{REFERÊNCIAS BIBLIOGRÁFICAS}

Association Official Analytical Chemists: Official Methods of analysis (1980) 13 ed. Washinghton DC. AOAC. 1115p.

Dawson DP, Morrill JL, Reddy PG, Minocha HC \& Ramsey HA (1988) Soy protein concentrate and heated soy flours as protein sources in milk replacer for preruminant calves. Journal of Dairy Science, 71:1301-1309.

Lalles JP, Toullec R, Branco Pardal P \& Sissons JW (1995) Hydrolyzed soy protein isolate sustains high nutritional performance in veal calves. Journal of Dairy Science, 78:194204.

Lammers BP, Heinrichs AJ \& Aydin A (1998) The effect of whey protein concentrate or dried skim milk in milk replacer on calf performance and blood metabolites. Journal of Dairy Science, 81:1940-1945

Plaza J \& Fernandez E (1999) Weaning weight and feed consumption on performance of female holstein calves. Cuban Journal of Agricultural Science, 33:37-40.

Quigley III JD, Smith ZP \& Heitmann RN (1991) Changes in plasma volatile fatty acids in response to weaning and feed intake in young calves. Journal of Dairy Science, 74:258-263.

SAS User's Guide (1997) Statistics, Version 6.12. Edition 1997. SAS Inst., Inc., Cory, NC.

Seegraber FJ \& Morril JL (1982) Effect of soy protein on calves intestinal absorptive ability and morphology determined by scanning electron microscopy. Journal of Dairy Science, 65:1962-1970.

Silva AG, Huber JT \& DeGregorio RM (1986) Influence of substituitin two types of soybean protein for milk protein on gain and utilization of milk replacers in calves. Journal of Dairy Science, 69:172-180.

Virtala AMK, Mechor GD, Gröhn YT \& Erb HN (1996) The effect of calfhood diseases on growth of female dairy calves during the first 3 months of life in New York state. Journal of Dairy Science, 79:1040-1049. 